\title{
GALL-STONE ILEUS RECURRENCES AND MULTIPLE STONES
}

\author{
R. V. Fiddian, F.R.C.S. \\ Senior Surgical Registrar, St. Bartholomew's Hospital; Late Surgical Registrar, Norfolk and Norwich Hospital
}

Recurrence of gall-stone ileus in the immediate post-operative period has been reported only very occasionally (Brockis and Gilbert, 1957; Grey Turner, 1932; Hand and Gilmore, 1943; Foss and Summers, 1942) and is usually the result of missing a second stone in the small bowel at the first operation. Recurrence after months or years is exceptionally rare and is due to further stones finding their way into the bowel from the gallbladder. This paper reports 13 cases of gall-stone ileus, including two cases of recurrence, one after nine years (Case I) and one after three months (Case 6 and 6a), and three cases in which two stones were found in the small intestine at operation (Cases 3, Io and 13 ). The three cases illustrate obstruction by the proximal of two stones (Case I0), obstruction by the distal of two stones (Case 13), and closed loop obstruction between two impacted stones (Case 3).

The cases are briefly set out in the table. They were admitted to the Norfolk and Norwich Hospital in a ro-year-period, April 1948 to March $195^{8}$.

\section{Discussion \\ Incidence}

There were 13 cases of gall-stone ileus in a ro-year period representing about I per cent. of all cases of intestinal obstruction. In the same period mesenteric infarction was three times and volvulus six times as common as gall-stone ileus. Vick (1932) found 2 per cent. of a large series of all types of obstruction to be due to gall-stones. However, as has been pointed out, nearly 25 per cent. of all small bowel obstructions in patients over 70 years of age, excluding strangulated herniae, were due to gall-stone ileus in his $1925-30$ series.

The equivalent figure for women alone would obviously be even higher.

\section{Age and Sex}

The average age of the patients in this series was 71 . The range was 43 to 86 and 10 of the 13 cases were over 70.

There were 12 women and one man.

\section{Mortality}

Four deaths out of 13 cases give a mortality of 3 I per cent., roughly the same as in a collected series $1940-56$ by Brockis and Gilbert (1957) but less than half Vick's (1932) figure of 70 per cent. for $1925-30$.

\section{Recurrence}

Case I was relieved of obstruction by gall-stone in the ileum nine years previously in the same hospital and made an excellent recovery. There was no mention in the operation note of that time about the gall-bladder area, and on subsequent follow-up the patient was symptom free and cholecystectomy was not advised. The patient was again successfully treated by operation for this second attack of gall-stone ileus, and again there was no mention in the operation note of the gallbladder. Presumably, in view of her age (70), interval cholecystectomy was not advised.

Case 6 made a satisfactory recovery after her operation on 26.7 .52 , when an obstructing stone in the ileum was removed. At this operation a hard mass obscured by adhesions was palpable in the gall-bladder region. The patient was readmitted three months later with a recurrent gallstone obstruction, the stone being impacted in the jejunum $3 \mathrm{ft}$. below the duodeno-jejunal flexure. The operation was difficult because of adhesions, and resection of a loop of bowel and anastomosis became necessary as a result of damage to its blood supply by dissection. Post-operative progress was satisfactory until the second day, when she had what was thought to be a coronary thrombosis and died the next day.

Rogers and Carter (1958) could find in the literature only seven cases of gall-stone ileus recurring three months or longer after a previous operation for the same condition. The longest interval recorded was 13 months (Noskin and Tannenbaum, 1952).

\section{Pathology}

In Case 13 a fistulous connection between the fundus of the gall-bladder and the duodenum was 


\begin{tabular}{|c|c|c|c|c|c|c|c|c|c|c|c|c|c|c|}
\hline 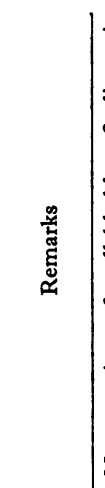 & 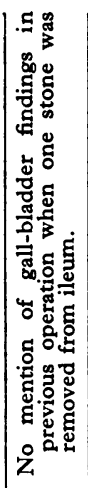 & 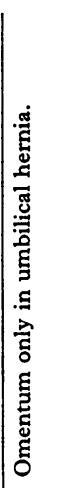 & 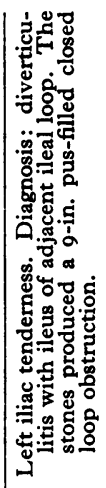 & 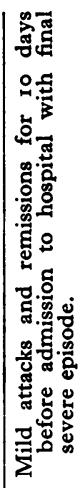 & & 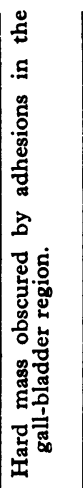 & 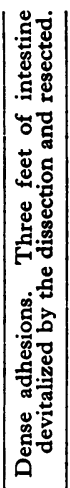 & & 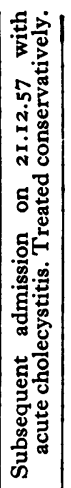 & 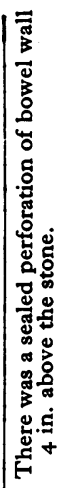 & 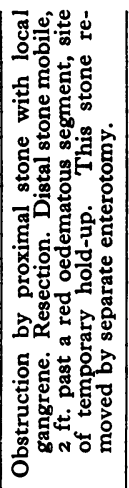 & & 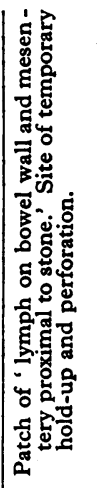 & 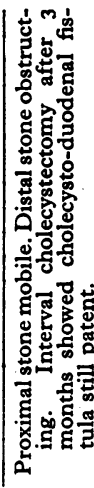 \\
\hline 密要 & $\leadsto$ & $a$ & a & $\simeq$ & $\simeq$ & 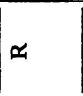 & $\theta$ & $\not$ & $\approx$ & $\theta$ & $\approx$ & $\approx$ & $\approx$ & $\simeq$ \\
\hline 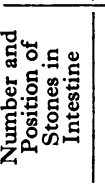 & 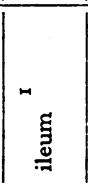 & $\stackrel{\Xi}{=}$ & 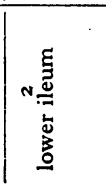 & Е & 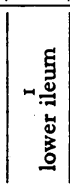 & $\stackrel{5}{\Xi}$ & 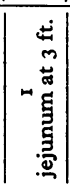 & 秭 & 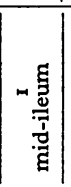 & 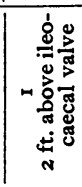 & 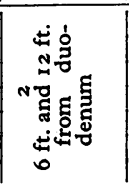 & 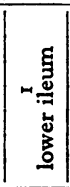 & $M$ & 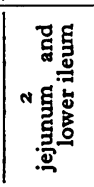 \\
\hline 窝 & 1 & 1 & 1 & 1 & 1 & 1 & 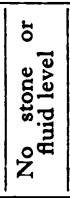 & 1 & 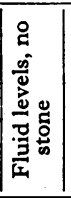 & 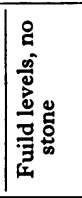 & 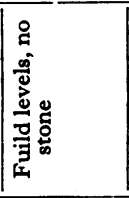 & 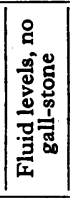 & 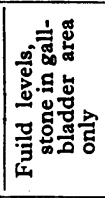 & 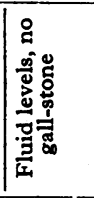 \\
\hline 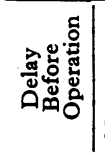 & $\mid$ & 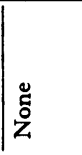 & 离 & 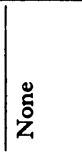 & $\mid \begin{array}{l}: \\
\text { z̆ }\end{array}$ & 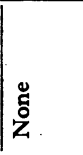 & 芩 & 吾 & 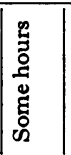 & 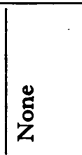 & 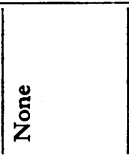 & 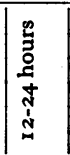 & 荇 & 号 \\
\hline 曾兽 & 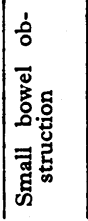 & 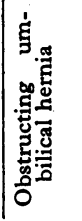 & 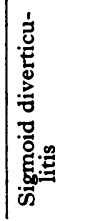 & 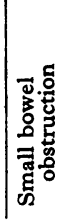 & 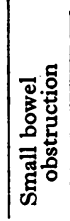 & 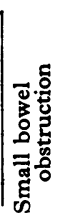 & 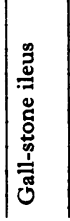 & $\sim$ & 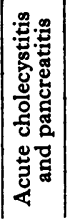 & 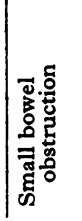 & 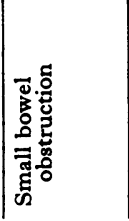 & 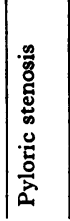 & 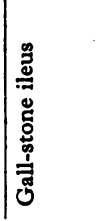 & 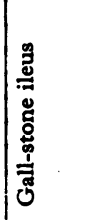 \\
\hline 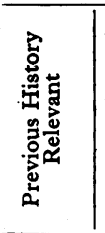 & 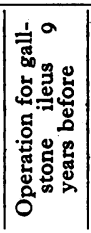 & 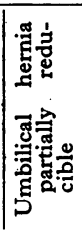 & 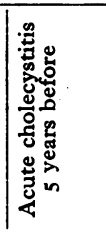 & $\bar{z}$ & 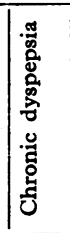 & 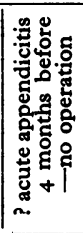 & 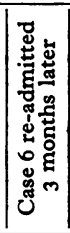 & 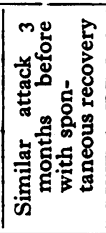 & 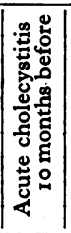 & | & 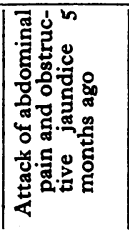 & 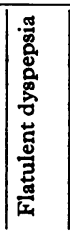 & $\overline{\mathbf{z}}$ & 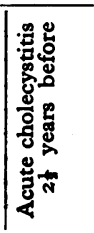 \\
\hline 焉 & 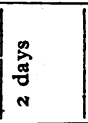 & 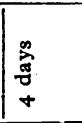 & 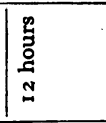 & 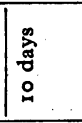 & 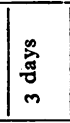 & 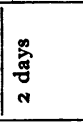 & 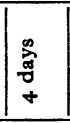 & $\mid \begin{array}{l}0 \\
0 \\
0 \\
\\
\end{array}$ & dु & $\begin{array}{l}\text { 离 } \\
\text { क्ष } \\
\text { in }\end{array}$ & 吾 & 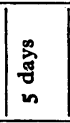 & 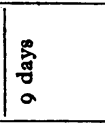 & " \\
\hline$\stackrel{8}{4}$ & 웅 & $\infty$ & $\infty$ & $\approx$ & $\approx$ & 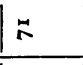 & 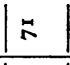 & $N$ & $\infty$ & $\mid \infty$ & | & ปี & \pm & 7 \\
\hline ڤั & w & a & $\Sigma$ & is & 14 & 山 & is & is & w & I & is & is & is & 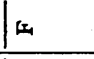 \\
\hline ڤ̆ & $\begin{array}{l}\infty \\
\dot{q} \\
+ \\
+ \\
+\end{array}$ & 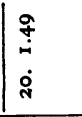 & $\mid \begin{array}{l}\stackrel{0}{a} \\
\dot{1} \\
\dot{1}\end{array}$ & $\begin{array}{l}\stackrel{0}{\leftrightarrow} \\
\dot{\alpha} \\
\dot{+}\end{array}$ & $\mid \begin{array}{c}0 \\
0 \\
0 \\
0 \\
0 \\
\end{array}$ & $\begin{array}{l}\text { ஸे } \\
\dot{\sim} \\
\dot{\alpha}\end{array}$ & 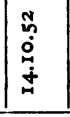 & $\begin{array}{l}\dot{m} \\
\infty \\
\dot{a} \\
\dot{a}\end{array}$ & $\begin{array}{l}\ddot{n} \\
\dot{+} \\
\dot{m}\end{array}$ & $\begin{array}{l}\hat{n} \\
a \\
\dot{n} \\
\end{array}$ & & 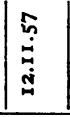 & 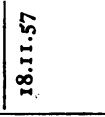 & 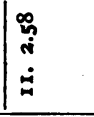 \\
\hline జ & - & N & $m$ & + & in & 0 & ๓ & r & $\infty$ & $a$ & 웅 & $=$ & $\cong$ & $m$ \\
\hline
\end{tabular}

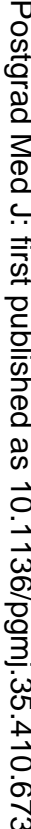

옥

우구

Ф

응

웅

응

의 윽

$\sum$

o

용

음

킁

흘

항

3

ㅇํㅀ

옥

금

กั

ㅇำ

产

$\stackrel{0}{\frac{1}{D}}$ 
demonistrated at subsequent cholecystectomy, and there seems to be no doubt that this is the usual route by which the gall-stones gradually ulcerate in these cases. The sites of obstruction ranged from 3 in. below the duodeno-jejunal flexure to 18 in. above the ileo-caecal valve, the majority being described in the lower ileum without detailed localization. Obstruction by gall-stone has been reported in the duodenum (Foss and Summers, 1942) and the colon (Grey Turner, 1932; Lloyd Williamson, 1952).

The obstruction seems to be, at least in part, due to spasm of that part of the bowel containing the stone, the size of which might not appear large enough to cause a completely mechanical obstruction. If the spasm is relieved, the stone may move on but may leave some ulceration or even perforation behind (Cases 9, Io and 12). If the spasm is at any time unrelieved for long enough to produce severe ulceration and gangrene, then resection of that segment of bowel may be necessary at operation (Case 10). Only one of Vick's (1932) 47 cases required anastomosis of bowel.

\section{Multiple Stones}

In three of the cases reported in this paper there were two stones in the small intestine at operation (Cases 3, ro and 13). In Case 3 the two stones were impacted in the lower ileum 9 in. apart and formed a short closed loop obstruction, the contents of which had the appearance of pus when released. The stones were removed through one incision. The patient died the day after operation, largely as a result of the delay in coming to operation. In Case ro obstruction was due to an impacted stone and there was local gangrene of the jejunum where the stone had ulcerated through all but the serosa. A few inches of jejunum, including the stone, were resected and continuity restored with end-to-end anastomosis. Another gall-stone was lying free in the small intestine $6 \mathrm{ft}$. further on and this stone had obviously been arrested $2 \mathrm{ft}$. more proximally, where the bowel was red and oedematous and the lumen was narrowed sufficiently to prevent the 'milking' of the distal stone upwards. This stone was therefore removed by separate enterotomy. The patient made an uneventful recovery. In Case 13 the obstruction was due to the distal of two stones which were in the lower ileum. The proximal stone in the jejunum was free in the lumen. The stones were manoeuvred together and removed by enterotomy just proximal to the site of obstruction. Post-operative recovery was uneventful and the patient was re-admitted three months later for cholecystectomy. At this operation a narrow fistula between the fundus of the gall-bladder and the duodenum was demonstrated, the fibrous contracted gall-bladder with a few small stones being removed and the duodenal opening oversewn. Foss and Summers (1942) found only four cases with two stones in the small bowel in 150 cases. Grey Turner (1932) had a case with two enormous stones in the transverse colon, and Wakely and Willway (1935) reported a case of gallstone ileus, a second stone being present in the rectum. Drew (1925) described a case with two stones in the jejunum, the upper one causing obstruction, a similar finding to that in Case ro.

\section{Diagnosis}

A correct pre-operative diagnosis was made in Cases 6a, 12 and 13. A previous history of chronic dyspepsia was obtained in three cases, and four other cases reported an acute inflammatory episode from five years to four months previously and presumably arising in the gall-bladder. One case had a history of operation for gall-stone ileus nine years before and one case had a transient similar attack to the present one three months before admission. The diagnosis of small intestinal obstruction was mostly straightforward and was confirmed by plain X-ray in all but one of the seven cases for which $\mathrm{X}$-rays are still available. One gall-stone only was visible and that appeared to be in the gall-bladder (Case 12). In no case was there any convincing appearance of gas in the bile ducts or gall-bladder on X-ray (Rigler et al., 194I). As with so many comparatively rare conditions the most important single factor in diagnosis is that the condition be called to mind. It would seem that in very elderly women, in the absence of strangulated hernia, previous abdominal operation (adhesions), or signs of malignancy (anaemia, weight loss), small bowel obstruction is probably due to a gall-stone.

\section{Treatment}

Treatment is operation as soon as the patient is fit for it, and this series of cases illustrates the importance of thoroughly examining the entire bowel for other stones or any lesion of the bowel wall due to temporary arrest of the stone. There is, however, some disagreement about the management of the gall-bladder and its residual stones if any. Wright and Trafford (1953) considered that the cholecysto-duodenal fistula would close spontaneously, but this is probably unlikely if there are further stones in the gall-bladder. Fraser (1954) and Brockis and Gilbert (1957) suggest removal of a large stone if felt in the gall-bladder, the patient's condition permitting, at the time of the first operation. Fraser also reported exploration of the gall-bladder as a second-stage procedure following operative relief of gall-stone ileus. In this series, of the two patients under 60 , one died and the 
other, aged 43, was submitted to interval cholecystectomy (Case 13 ). The one patient in her sixties and the remainder of those who survived, all over 70 , were not advised to have further surgery. One of these latter cases was the recurrence after nine years. Another had a recurrence after three months and died on the third day after the second operation. This patient was $7 \mathrm{I}$ and her death, thought to be due to post-operative coronary thrombosis, must be set against the anticipated mortality if all the very elderly cases were submitted to cold but difficult cholecystectomies, or if the original operation for obstruction were prolonged and extended by exploration of the gallbladder area. It would seem reasonable to advise subsequent cholecystectomy in the younger patients only.

\section{Summary}

Thirteen cases of gall-stone ileus are presented.

One case was a recurrence of gall-stone ileus after a period of nine years. Another case was readmitted with a recurrence after three months.

Three cases in which there were two stones present in the small intestine at operation illustrate obstruction by the upper of two stones, obstruction by the more distal of two stones, and closed loop obstruction between two impacted stones.
In three cases there were lesions of the bowel wall above the site of obstruction due to temporary arrest of a stone.

The mortality was 3 I per cent.

The problem of residual stones in the gallbladder is discussed.

Thanks are due to Mr. J. M. Ridley Thomas, Mr. N. J. Townsley, Mr. A. B. Birt and Mr. J. P. Stephens for permission to report cases in their care.

\section{BIBLIOGRAPHY}

BROCKIS, J. G., and GILBERT, M. C. (1957), Brit. Ұ. Surg., 4 $46 \mathrm{x}$.

DREW, D. (1925), Ibid., 12, 803.

FOSS, H. L., and SUMMERS, J. D. (1942), Ann. Surg., 115, 721 . FRASER, W. J. (1954), Brit. F. Surg., 42, 210.

HAND, B. H., and GILMORE, W. E. (1943), Amer. F. Surg., 59, 72.

NOSKIN, E. Q., and TANNENBAUM, W. C. (1952), Surgery, 3I, 599.

RIGLER, L. G., BORMAN, G. N., and NOBLE, J. F. (194I), 7. Amer. med. Ass., 117,1753 .

ROGERS, F. A., and CARTER, R. (1958), Amer. F. Surg., 96, 379. TURNER, G. GREY (1932), Brit. F. Surg., 20, 26.

VICK, R. (1932), Brit. med. F., ii, 546.

WAKELEY, C. P. G., and WILLWAY, F. W. (1935), Brit. F. Surg. 23, 377 .

WILLIAMSON, LLOYD J. C. F. (1952), Ibid., 39, 339.

WRIGHT, P. J. M., and TRAFFORD, P. A. (1953), Ibid., 4I, 6.

\section{RENAL DISEASE}

(Postgraduate Medical Journal, November 1959)

Price 6s. 6d. post free

RECENT DEVELOPMENTS IN THE STUDY OF THE KIDNEY

A. A. G. Lewis, B.Sc., M.D., M.R.C.P.

RENAL BIOPSY AND

GLOMERULONEPHRITIS

J. H. Ross, M.D., M.R.C.P.

RECENT ADVANCES IN THE TREATMENT OF RENAL DISEASE

A. G. Spencer, M.D., M.R.C.P.

\section{AORTOGRAPHY}

I. H. Griffiths, F.R.C.S.

\section{HAEMODIALYSIS}

F. M. Parsons, B.Sc., M.B., Ch.B.

\section{DIURETICS}

H. G. Lloyd-Thomas, M.A., M.B., M.R.C.P.

\section{URINARY DIVERSION}

John Hopewell, F.R.C.S.

\section{RENAL ARTERY STENOSIS}

Kenneth Owen, M.S., F.R.C.S. 